\title{
Comparative mapping and validation of multiple disease resistance QTL for simultaneously controlling common and dwarf bunt in bread wheat
}

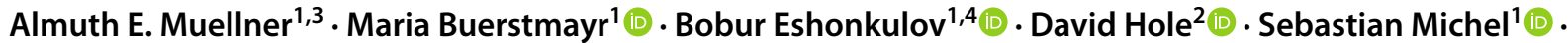 \\ Julia F. Hagenguth ${ }^{1,5} \cdot$ Bernadette Pachler $^{1,6} \cdot$ Ricarda Pernold $^{1,7} \cdot$ Hermann Buerstmayr $^{1}$ (i)
}

Received: 15 May 2020 / Accepted: 13 October 2020 / Published online: 29 October 2020

(c) The Author(s) 2020

\begin{abstract}
Key message Resistance QTL on chromosomes $1 \mathrm{AL}$ and 7AL are effective against common and dwarf bunt, QTL on $1 B S$ affects common bunt and QTL on 7DS affects dwarf bunt in bread wheat.

Abstract Common bunt, caused by Tilletia caries and T. laevis, and dwarf bunt, caused by $T$. controversa, negatively affect grain yield and quality of wheat and are particularly destructive in low-input and organic production systems. Two recombinant inbred line (RIL) populations derived by crossing the highly and durably resistant cultivars 'Blizzard' and 'Bonneville' to the susceptible cultivar 'Rainer' were evaluated for their resistance to common and dwarf bunt in artificially inoculated field and greenhouse trials over two growing seasons and genotyped with a $15 \mathrm{~K} \mathrm{SNP}$ array. Bunt resistance QTL were mapped to chromosomes $1 \mathrm{AL}, 1 \mathrm{BS}, 7 \mathrm{AL}$ and 7DS. Common bunt resistance was regulated by the major QTL QBt.ifa-lBS and QBt. ifa-1AL together with the moderate effect QTL $Q B$ t.ifa-7AL. Dwarf bunt resistance was on the other hand regulated by the QTL QBt.ifa-1AL, QBt.ifa-7AL and QBt.ifa-7DS. Common bunt resistance QTL exhibited pronounced epistatic effects, while epistatic effects were of smaller magnitude for dwarf bunt QTL. Kompetitive Allele-Specific PCR (KASP) markers were developed from SNPs associated with bunt resistance QTL and successfully used for QTL validation in an independent set of RILs. These KASP markers have the potential to support targeted introgression of QTL into elite wheat germplasm and accelerate breeding for enhanced bunt resistance. Durable protection against both common and dwarf bunt can be achieved by combining multiple resistance genes in the same genetic background.
\end{abstract}

\section{Introduction}

Communicated by Kevin Smith.

Almuth E. Muellner and Maria Buerstmayr contributed equally to this work.

Electronic supplementary material The online version of this article (https://doi.org/10.1007/s00122-020-03708-8) contains supplementary material, which is available to authorized users.

Maria Buerstmayr

maria.buerstmayr@boku.ac.at

1 Institute for Biotechnology in Plant Production, University of Natural Resources and Life Sciences, Konrad Lorenz Straße 20, 3430 Vienna, Tulln, Austria

2 Utah State University, 2325 Old Main Hill, Logan, UT 84322, USA

3 Present Address: Saatzucht Donau GesmbH. \& CoKG, Saatzuchtstrasse 11, 2301 Probstdorf, Austria
The first historical records of bunts in wheat date back to early Greek and Roman times, and bunted heads have likely been observed since the beginning of wheat cultivation (Chen et al. 2016; Christensen 1957; Woolman and Humphrey 1924). Bunts were amongst the most destructive fungal diseases worldwide before the introduction of chemical

4 Present Address: Samarkand Branch of Tashkent State University of Economics, Professors Street 51, 140147 Samarkand, Usbekistan

5 Present Address: Division of Plant Breeding Methodology, University of Goettingen, Carl-Sprengel-Weg 1, 37075 Göttingen, Germany

6 Present Address: Saatbau Linz eGen, Breeding Station Schoenering, Angerweg 19, 4073 Wilhering, Austria

7 Present Address: Mauerbachstraße 5, 1140 Wien, Austria 
seed treatments in the 1950s (Aboukhaddour et al. 2020; Matanguihan et al. 2011; Russell 2005). Breeding efforts for host plant resistance and research on pathogen biology have steadily decreased with the routine use of chemical seed treatment. However, bunt diseases have continued to threaten low-input farming systems and have been re-emerging in organic farming, which restricts or prohibits chemical disease management. Given the limited options for organic certified seed treatments and insufficient resistance levels of currently grown wheat cultivars in many areas of the world, breeding for bunt resistance has regained attention and become a high priority for organic wheat breeding (Borgen and Davanlou 2000; Matanguihan et al. 2011). Dwarf bunt (DB), caused by Tilletia controversa J.G. Kühn is restricted to regions with extended snow cover, while common bunt (CB), caused by T. caries (DC.) Tul. \& C. Tul [syn. T. tritici (Bjerk.) G.Winter] and T. laevis J.G. Kühn [syn. T. foetida (Wallr) Liro] occurs in all wheat growing regions worldwide (Goates 1996; Saari et al. 1996). DB infection results from soil-borne $T$. controversa teliospores that can survive in the soil for over 10 years without losing viability, whereas CB is primarily caused by seed-borne inoculum (Borgen and Davanlou 2000; Goates 1996; Tyler and Jensen 1958). DB teliospores germinate following a preconditioning exposure to diffuse light and several weeks of stably cool temperatures of approximately $0-8{ }^{\circ} \mathrm{C}$, conditions that are most reliably provided by an unfrozen soil surface beneath continuous snow cover (Goates and Peterson 1999; Purdy and Kendrick 1963). Germination requirements for $\mathrm{CB}$ teliospores are less stringent and spores germinate at a wide range of soil temperatures with an optimum of approximately $5-10{ }^{\circ} \mathrm{C}$ (Goates 1996). After infection, CB and DB fungi grow systemically in the host plant until ovary formation, after which they convert the entire endosperm within the pericarp into a bunt ball (sorus). Bunt sori are almost entirely composed of teliospores and contain significant levels of trimethylamine, which give infected grains a strong odor of rotting fish. CB and DB can cause substantial yield losses and reduce grain quality when seed-lots are contaminated with bunt balls at levels as low as $0.05 \%$ (Gaudet and Puchalski 1989).

The development and deployment of bunt resistant cultivars is the most efficient and sustainable plant protection strategy and is thus pivotal for successful organic-certified seed production and wheat cultivation in farmers' fields. To date sixteen race-specific bunt resistance $(B t)$ genes (Btl to $B t 15$ and $B t P$ ) are known (Goates 1996, 2012) thereof, only Bt9 (Steffan et al. 2017; Wang et al. 2019), Bt10 (Laroche et al. 2000; Menzies et al. 2006) and Bt12 (Muellner et al. 2020) have been genetically mapped and linked markers are available for marker assisted selection (MAS). However, new pathotypes can evolve and overcome race-specific resistance genes, and new bunt races with virulence against one or more resistance genes have already been identified
(Goates 2012). Consequently, cultivars that rely on single race-specific resistance genes may become susceptible due to pathogen adaptation. Pyramiding several race-specific $B t$ genes and combining them with partially effective, race-nonspecific resistance QTL confers complex, horizontal resistance that provides a more durable, long-lasting resistance.

Hence, quantitatively inherited resistance is complementary to race-specific $B t$ genes. To date, seven mapping populations and three hexaploid wheat association panels have been analyzed to dissect the genetic architecture of $\mathrm{CB}$ resistance, identifying a total of 24 QTL on 13 chromosomes (Bokore et al. 2019; Dumalasova et al. 2012; Fofana et al. 2008; Knox et al. 2013; Singh et al. 2016; Wang et al. 2009; Zou et al. 2017). Chromosome 1B is strongly implicated in resistance, as several independent mapping populations have detected both minor and major QTL on 1B (Dumalasova et al. 2012; Fofana et al. 2008; Galaev et al. 2018; Singh et al. 2016; Wang et al. 2009; Zou et al. 2017). A wheat panel comprising 125 synthetic hexaploid wheats (Bhatta et al. 2018) and a diversity panel of 330 Nebraska winter wheat genotypes (Mourad et al. 2018) have demonstrated wide genetic variation and quantitative inheritance of $\mathrm{CB}$ resistance.

In comparison, genetic studies of DB resistance have been limited, likely due to the challenging nature of DB teliospore germination and subsequent disease screening. To date, only four QTL mapping studies for DB resistance have been published. Wang et al. (2019) identified a major QTL on 6DL and one on 7AL, and the QTL on 6DL most likely corresponds to $B t 9$. Chen et al. (2016) mapped a major effect QTL to the distal end of chromosome 7DS and two minor effect QTL, one on chromosome 1A and one on 2B. Muellner et al. (2020) confirmed Bt12 as being highly effective against CB and moderately effective against $\mathrm{DB}$ and placed it on 7DS, in proximity to the major DB QTL reported by Chen et al. (2016). Lastly, a diversity panel of 292 wheat accessions revealed 28 accessions that were highly resistant and largely of Turkish origin and two loci associated with DB resistance on chromosome 6D (Gordon et al. 2020).

Despite clear differences in infection biology and germination requirements, the three bunt pathogens $T$. controversa, $T$. caries, and $T$. laevis are closely related and are able to hybridize (Holton 1954; Nguyen et al. 2019). This close relationship is of particular relevance in resistance breeding because host plant resistances to $\mathrm{CB}$ and $\mathrm{DB}$ are putatively controlled by the same genes in a classic genefor-gene host-pathogen interaction framework (Flor 1956; Goates 1996, 2012; Hoffmann and Metzger 1976). The main objectives of this study were thus to (i) identify, characterize and compare QTL for resistance to CB and DB using two RIL populations derived from crosses of bunt resistant cultivars Blizzard and Bonneville to the bunt susceptible cultivar Rainer, and (ii) develop and validate KASP markers 
targeting CB and DB resistance QTL in an independent set of RILs to facilitate molecular breeding for improved and durable bunt resistance by pyramiding genes/QTL.

\section{Material and methods}

\section{Plant material}

\section{Mapping populations}

The two North American cultivars Blizzard and Bonneville were crossed as female parents to the Austrian cultivar Rainer to generate the two mapping populations MP-BLI and MP-BON comprising 120 and $85 \mathrm{~F}_{5: 7}$ RILs, respectively. 'Blizzard' and 'Bonneville' are awned hard red winter wheat cultivars, highly adapted to dryland areas, and display excellent milling and baking quality according to North American standards. Blizzard and Bonneville, released in the USA by Idaho AES in 1989 (Sunderman et al. 1991) and by the USDA-ARS in 1994 (Souza et al. 1995), respectively, are closely related (Table $\mathrm{S} 1$, https://wheatpedigree. net/) and have maintained a high level of resistance to both $\mathrm{CB}$ and DB since their registration. Rainer is an awnless winter wheat cultivar released by Saatzucht Donau GesmbH \& CoKG (Austria) in 2006. Rainer possesses well-adapted agronomic traits for cultivation in Austria but is highly susceptible to CB and DB.

\section{Validation population}

The validation population consisted of $85 \mathrm{BC}_{1} \mathrm{~F}_{5}$ RILs and comprised 18, 27, and $40 \mathrm{BC}_{1} \mathrm{~F}_{5}$ RILs derived from crossing Rainer/Blizzard//Midas, Rainer/Bonneville//20568.1.2, and Midas/Bonneville//Rainer, respectively. 'Midas' is an awned and locally adapted Austrian quality wheat cultivar released by Saatzucht Donau GmbH \& CoKG (Austria) in 2008. The experimental line '20568.1.2' was selected for its high level to Fusarium head blight resistance from the cross Capo/Sumai-3. Both, Midas and 20568.1.2 are highly susceptible to CB and DB.

\section{Bunt differential lines}

Fourteen bunt differential lines, each carrying one of the bunt resistance genes Bt1-Bt13 and BtP (Goates 2012), were used to monitor the virulence spectrum of the $T$. caries and T. controversa inoculum that was used for artificial inoculations. In accordance to Goates (2012) the reaction of the spore mixtures was considered avirulent to a specific bunt differential line when $10 \%$ or less of the spikes were diseased, and virulent if the disease incidence exceeded $10 \%$.

\section{Field experiments and disease evaluations}

The mapping populations MP-BLI and MP-BON were tested for CB resistance in 2015 and 2016 in two artificially inoculated field trials (CB.f15, CB.f16) and one artificially inoculated greenhouse experiment (CB.gh16) and screened for DB resistance in two artificially inoculated field trials (DB.f15 and DB.f16). The validation population was evaluated for $\mathrm{CB}$ resistance in one field trial in 2018 (CB.f18). RILs were grown along parental lines, control standards, and the bunt differential lines in each experiment. All trials were laid out as randomized complete block designs with two blocks (i.e. replications). For each experiment and each population, RILs were planted at $n=1 / \mathrm{rep}$, parental lines were planted at $n=2 / \mathrm{rep}$, and the susceptible standard 'Capo' was planted at $n=8-10$ / rep. Each line of the bunt differential set was planted at $n=1 /$ rep. Susceptible control standards 'Midas', 'Pannonikus' and 'Saturnus', and resistant control standards 'Globus', 'Golden Spike' and 'Weston' were planted at $n=1 /$ rep in all field trials. Capo is susceptibility to both, $\mathrm{CB}$ and DB and was chosen as the main susceptible control standard due to its extensive use in organic winter wheat production in Austria.

CB trials were conducted at the experimental station of IFA-Tulln, Austria ( $48^{\circ} 19^{\prime} 05^{\prime \prime} \mathrm{N} 16^{\circ} 04^{\prime} 10^{\prime \prime} \mathrm{E}$, elevation: 177 masl). Originally, $T$. caries spores were collected at three different locations in Austria, representing the CB race spectrum prevalent in eastern and western Austria, and teliospores from these isolates were mixed for seed inoculation. CB spores were harvested from previous season's infected plants displaying a typical common bunt phenotype of a diverse set of susceptible genotypes and stored under dry conditions at room temperature. Inoculation of seeds was performed according to the protocol developed by Goates (1996), applying a final concentration of $0.75 \mathrm{~g}$ teliospores per $100 \mathrm{~g}$ seeds. Each genotype was tested in a $0.5 \mathrm{~m}^{2}$ plot consisting of two rows, each with a length of $1.5 \mathrm{~m}$ and spaced $17 \mathrm{~cm}$ apart, with approximately 70 plants per row. CB nurseries were established in early November by sowing $6 \mathrm{~g}$ of inoculated, spore-coated seeds per plot. For the greenhouse experiment, inoculated seeds were germinated in early December in seedling-trays (150 plant holes per seedling-tray, top diameter of hole: $3 \mathrm{~cm}$, height: $4 \mathrm{~cm}$ ) and subjected to vernalization for eight weeks. Upon vernalization, 10 plantlets per genotype were transplanted into 7.51 pots filled with a standard gardening soil substrate consisting of $75 \%$ heat-sterilized recycled compost, $23 \%$ peat, and $2 \%$ silica sand and moved to the greenhouse. Pots served as experimental units and were arranged in a completely randomized design with two replicates. The temperature in the greenhouse was maintained at $22 / 18{ }^{\circ} \mathrm{C}$ (day/night) with a $16 \mathrm{~h}$ photoperiod at $15,000 \mathrm{~lx}$. 
DB resistance was evaluated at the Utah State University Research Farm in Logan, Utah, USA (41 ${ }^{\circ} 45^{\prime} 46.46^{\prime \prime}$ N 111 ${ }^{\circ} 48^{\prime} 54.98^{\prime \prime} \mathrm{W}$, elevation: 1400 masl). This location is known for having long periods of snow cover, which is essential to induce high levels of dwarf bunt disease (Chen et al. 2016). Sowing took place at the beginning of October. According to a protocol developed by Goates (1996), the disease nurseries were soil inoculated after seedling emergence prior to snow cover in early November, with a water suspension of a $T$. controversa teliospore race mix, representing the virulence spectrum of races found in the USA (Chen et al. 2016). Each genotype was tested in a $1 \mathrm{~m}$ single row at a seeding rate of $2 \mathrm{~g}$ per row. Individual rows were inoculated by spraying approximately $100 \mathrm{ml}$ water spore suspension containing $1.3 \mathrm{~g}$ spores per $1 \mathrm{~m}$ plot resulting in an application of between 2.5 and $3.5 \times 10^{8}$ teliospores for each meter row. $\mathrm{CB}$ and $\mathrm{DB}$ incidence were determined as percentage of infected spikes relative to the total number of spikes within a plot at plant maturity. A spike was considered infected when containing at least one bunted spikelet.

\section{Phenotypic analysis}

Each population was analysed separately. Best linear unbiased estimates (BLUEs) for individual environment were calculated with a linear mixed model of the form:

$P_{i k}=\mu+G_{i}+R_{k}+e_{i k}$

where $P_{i k}$ denotes the observed phenotypic value, $\mu$ the population mean, $G_{i}$ the effect of the $i$ th genotype, $R_{k}$ the effect of the $k$ th replicate and $e_{i k}$ the residual effect. The model was extended for the across environment analysis to:

$P_{i j k}=\mu+G_{i}+E_{j}+E_{j}\left(R_{k}\right)+G_{i} \times E_{j}+e_{i j k}$

where $P_{i j k}$ designates again the observed phenotypic value, $\mu$ the population mean, $G_{i}$ the effect of the $i$ th genotype, $E_{j}$ the effect of the $j$ th environment, $\mathrm{E}_{\mathrm{j}}\left(R_{k}\right)$ the effect of the $k$ th replicate within the $j$ th environment, $G_{i} \times E_{j}$ the $i j$ th effect of the genotype-by-environment interaction and $e_{i j k}$ the residual effect. The genotype effect was treated as fixed to derive BLUEs and random to estimate the genetic variance, while all other effects were modelled as random in both models. Fixed and random effects of the models were tested one by one using the Wald F-test. Broad-sense heritability $\left(\mathrm{H}^{2}\right)$ was computed as suggested by Piepho and Möhring (2007):

$H^{2}=\sigma_{G}^{2} /\left(\sigma_{G}^{2}+1 / 2 \mathrm{MVD}\right)$

where $\sigma_{G}^{2}$ designates the genetic variance and MVD is the mean variance of a difference of the BLUEs. Pearson correlation coefficients were calculated between experiments and across CB and DB environments using BLUEs. All statistical analyses were conducted in R 3.1.3 (R Core Team 2016) using the package ASReml3 for mixed model analysis (Gilmour et al. 2015).

\section{Molecular marker analysis}

Genomic DNA was extracted using a modified CTAB method (Saghai-Maroof et al. 1984). Genotyping of RILs and parents of MP-BLI and MP-BON was performed using the Illumina Infinium $15 \mathrm{~K}$ wheat SNP array offered by Trait Genetics GmbH (Gatersleben, Germany, https://www. traitgenetics.de) comprising 12,907 gene-associated SNPs. In addition, all lines were genotyped with SSR markers gwm264, gwm374 (Röder et al. 1998), and barc128 (Lowe et al. 2011). These markers were previously suggested to be associated with bunt resistance (Wang et al. 2009) and screened as polymorphic between the parents in pre-tests. Marker data were quality checked prior to linkage map construction and QTL mapping, whereby RILs with more than $20 \%$ missing marker data points were removed, RILs sharing more than $95 \%$ of markers were considered as the same genotype, and markers with significant segregation distortion $(p<0.001)$ and more than $20 \%$ missing values were discarded.

\section{Linkage map construction}

Genetic maps of populations MP-BLI and MP-BON and a consensus map across both populations (MP-CON) were calculated using the statistical package ASMap v0.4 (Taylor and Butler 2017) in the R environment (The R Core Team, 2016). The objective function was set to minimize the sum of recombination events between markers for map construction. First, robust linkage groups were constructed using a stringent threshold $\left(p<1 \times 10^{-8}\right)$ and assigned to particular wheat chromosomes based on the hexaploid consensus wheat map (Wang et al. 2014). Within linkage groups, markers were reordered at a less stringent threshold $\left(p<1 \times 10^{-6}\right)$. Genetic distances were calculated with the Kosambi mapping function. Physical bp positions of mapped SNP markers were derived from the IWGSC RefSeq v1.0 annotation hosted at https://wheat-urgi.versailles.inra.fr/Seq-Repository /Annotations (Alaux et al. 2018). Graphical representation of linkage groups and QTL positions, were drawn with MapChart 2.2. (Voorrips 2002).

\section{QTL analysis}

QTL analyses were performed with the R package $\mathrm{R} / \mathrm{qt}$ 1.46-2 (Broman et al. 2003). Genome wide QTL searches were conducted for each population separately using the population specific linkage maps and across populations using the consensus map. Analyses were conducted for CB 
and DB incidence BLUEs of individual experiments and the BLUEs across DB and CB field experiments. Missing genotypic information was imputed according to the multiple imputation method of Sen and Churchill (2001). In a first step, the main effect QTL were detected by composite interval mapping (CIM) using the Haley-Knott regression method. LOD significance thresholds of the respective trait, experiment and population for type I error rates at $\alpha<0.1$ and $\alpha<0.05$ were determined by running 1000 permutations. In a second step, multiple QTL models (MQM) were fitted including all significant QTL. MQM models were explored for the presence of further QTL and QTL-by-QTL interactions using addqtl and addint functions. Finally, trait and population specific MQM models were fitted including all significant QTL and QTL interactions. The overall fit of the full model against the null model was tested by ANOVA. The effect of the individual QTL were determined by comparing the full model and the model with the respective term omitted. LOD scores, estimated additive effects and percentage of the phenotypic variance explained by each QTL and QTL interaction were obtained from the drop-one ANOVA table of the MQM analysis. Confidence intervals were determined by the 1.5-LOD drop off support interval following van Ooijen (1992). QTL identified in individual populations with overlapping intervals were considered identical.

\section{KASP marker development}

Sequence information for KASP assays of the mapped resistance loci were derived from the publicly available data set on the Cereals DB website (www.cerealsdb.uk.net; Wilkinson et al. 2016). KASP assays for SNP markers were selected based on their genetic locations on the linkage maps of the MP-BLI and MP-BON populations and on their physical positions on the IWGSC RefSeq v1.0. KASP assays were screened for polymorphism between the resistance donor and the respective recipient parent alleles and tested for cosegregation with the corresponding SNP genotype calls from the MP-BLI and MP-BON mapping populations. The full set of winter wheat bunt differential lines and a diverse set of 57 genotypes (European and international wheat cultivars, gene bank accessions and experimental lines, Table S2) were also screened with these KASP assays to verify their applicability for MAS and gene pyramiding.

\section{QTL validation}

Markers positioned within QTL support intervals were selected for characterization of the validation population. Differences in CB incidence among genotypes grouped by QTL combination were compared with a Tukey HSD test at $p<0.05$.

\section{Results}

\section{Races' virulence phenotypes}

The $T$. caries race mix used for CB inoculations was virulent to $B t 2$ and $B t 7$ in field trial conditions and exhibited a broader virulence spectrum (virulent to $B t 2, B t 6, B t 7, B t 8$, $B t 9, B t 13$, and $B t P$ ) in the greenhouse. The $T$. controversa race mix used for DB field inoculations was virulent to $B t 1$, $B t 2, B t 4, B t 6$, and $B t 7$ (Table S3).

\section{Trait variations and trait correlations}

Quantitative variation was evident for CB and DB incidence in all trials, which generally followed a positively skewed continuous distribution with more than $50 \%$ of lines showing low ( $<10 \%$ bunt incidence) or no infection (Fig. 1). Blizzard and Bonneville were highly resistant with BLUEs less than $1 \%$ for $\mathrm{CB}$ and $\mathrm{DB}$ incidence, whereas Rainer was highly susceptible with BLUEs of $85 \%$ and $27 \%$ for $\mathrm{CB}$ and DB incidence, respectively (Table 1, Table S3). Average CB incidence levels were similar across field trials and populations and ranged from 12.3 to $13 \%$. The greenhouse trials were more diseased and had BLUEs of $26 \%$ for MP-BLI and $21.2 \%$ for MP-BON. BLUEs across populations for DB incidence varied between years, and were 9.9 and $6.3 \%$ in DB.f15 and 18.4 and 13\% in DB.f16 for MP-BLI and MPBON, respectively (Table 1). Genotype was the main source of variance for $\mathrm{CB}$ and $\mathrm{DB}$ incidence in both mapping populations (Table S4). Genetic variance was higher than genotype by environment variance, resulting in broad-sense heritabilities $\left(H^{2}\right)$ up to 0.94 for $\mathrm{CB}$ and 0.87 for DB incidence (Table 1). Individual experiments were highly significantly correlated in both populations $(r=0.95$ between field experiments; $r=0.80-0.84$ between field and greenhouse experiments). Likewise, DB experiments were highly correlated $(r=0.71$ for MP-BLI; $r=0.83$ for MP-BON). The correlations between BLUEs of CB and DB incidence across all experiments were $r=0.66$ and $r=0.38$ in the MP-BLI and MP-BON populations, respectively (Fig. 1, Table S5, S6).

\section{QTL analysis}

\section{Linkage map}

After quality control, 112 RILs and 4454 markers were used to construct the MP-BLI map, resulting in 31 linkage groups (LG) with a total map length of $3228 \mathrm{cM}$. Genetic map construction for MP-BON involved 85 RILs and 5020 markers and yielded a map with $34 \mathrm{LG}$ spanning $2576 \mathrm{cM}$. Seventy percent of all polymorphic markers were shared between the 


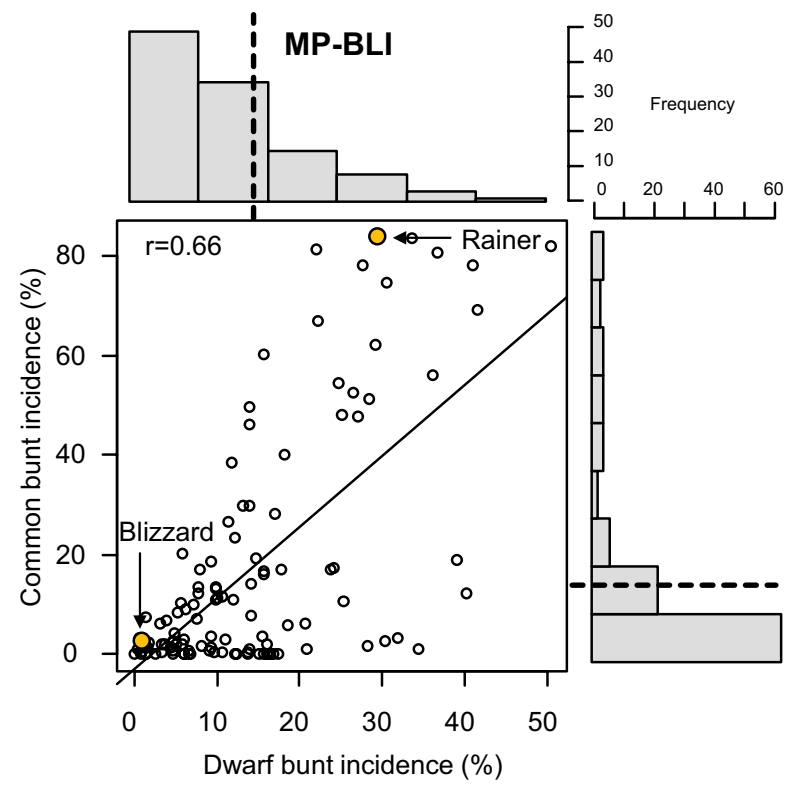

Fig. 1 Scatterplots of BLUEs of genotypes across experiments for common bunt incidence (\%) versus dwarf bunt incidence (\%) with marginal histograms of the two traits in the MP-BLI (left) and MP-

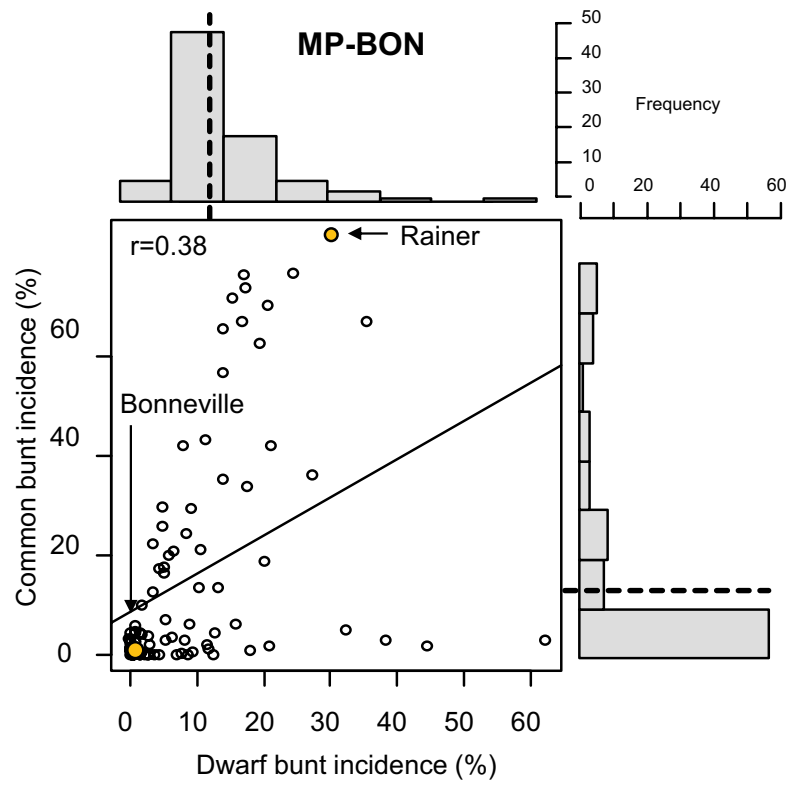

BON (right) mapping populations. Vertical dashed lines in histograms indicate population means

Table 1 Parental average as well as means, minimum and maximum values, and broad sense heritability $\left(\mathrm{H}^{2}\right)$ or repeatability $(\mathrm{r})$ of the mapping populations MP-BLI and MP-BON evaluated for common and dwarf bunt incidence in 2015 and 2016

\begin{tabular}{|c|c|c|c|c|c|c|c|c|c|c|c|c|c|}
\hline \multirow{2}{*}{$\begin{array}{l}\text { Trait } \\
\text { Experiment }\end{array}$} & \multicolumn{3}{|l|}{ Parents } & \multicolumn{5}{|c|}{ Population MP-BON } & \multicolumn{5}{|c|}{ Population MP-BON } \\
\hline & Blizzard & Bonneville & Rainer & Mean & Min & Max & LSD5 $^{\mathrm{c}}$ & $\mathrm{H}^{2} / \mathrm{r}$ & Mean & Min & Max & LSD5 $^{\mathrm{c}}$ & $\mathrm{H}^{2} / \mathrm{r}$ \\
\hline \multicolumn{14}{|c|}{ Common bunt incidence (\%) } \\
\hline CB.f15 & 1.3 & 0.0 & 81.2 & 13.0 & 0.0 & 79.3 & 6.3 & $0.99^{\mathrm{a}}$ & 12.5 & 0.0 & 83.1 & 7.5 & $0.98^{\mathrm{a}}$ \\
\hline CB.f16 & 0.0 & 0.0 & 82.0 & 12.4 & 0.0 & 87.9 & 6.1 & $0.99^{\mathrm{a}}$ & 12.3 & 0.0 & 80.8 & 7.4 & $0.98^{\mathrm{a}}$ \\
\hline CB.gh16 & 1.9 & 0.0 & 92.2 & 26.0 & 0.0 & 100.0 & 25.2 & $0.92^{\mathrm{a}}$ & 21.2 & 0.0 & 100.0 & 25.7 & $0.95^{\mathrm{a}}$ \\
\hline Overall mean & 1.1 & 0.0 & 85.0 & 17.2 & 0.0 & 84.2 & 16.8 & $0.94^{b}$ & 17.1 & 0.0 & 85.8 & 15.8 & $0.94^{\mathrm{b}}$ \\
\hline \multicolumn{14}{|c|}{ Dwarf bunt incidence (\%) } \\
\hline DB.f15 & 0.3 & 0.0 & 18.5 & 9.9 & 0.0 & 44.7 & 7.7 & $0.93^{\mathrm{a}}$ & 6.3 & 0.0 & 42.4 & 6.4 & $0.94^{\mathrm{a}}$ \\
\hline DB.f16 & 0.9 & 0.5 & 38.8 & 18.4 & 0.0 & 56.0 & 12.2 & $0.89^{\mathrm{a}}$ & 13.0 & 0.0 & 74.9 & 14.7 & $0.87^{\mathrm{a}}$ \\
\hline Overall mean & 0.6 & 0.3 & 26.9 & 14.2 & 0.0 & 50.4 & 12.4 & $0.83^{\mathrm{b}}$ & 9.5 & 0.0 & 62.1 & 11.5 & $0.87^{\mathrm{b}}$ \\
\hline
\end{tabular}

${ }^{\text {a }}$ Repeatability

${ }^{\mathrm{b}}$ Broad sense heritability

${ }^{\mathrm{c}}$ Least significant differences at $\alpha<0.05$

populations, and these 3,878 shared markers were used for calculating a consensus map across both populations. This consensus map (MP-CON) comprised 27 LGs representing 2877 cM (Online Resource Table S7).

\section{QTL for bunt resistance}

QTL analyses identified four QTL for bunt resistance that mapped to chromosomes $1 \mathrm{~A}, 1 \mathrm{~B}, 7 \mathrm{~A}$, and 7D, which were designated as QBt.ifa-1AL, QBt.ifa-1BS, QBt.ifa-7AL, and
QBt.ifa-7DS, respectively. Blizzard and Bonneville are closely related and share the same allele for $73 \%$ of all mapped SNP markers. The close genetic relationship was confirmed by the low dissimilarity index of 0.12 according Bray-Curtis (Bray and Curtis 1957). Blizzard and Bonneville shared the same SNP haplotype across all QTL intervals (Table S7). All resistance improving QTL alleles descended from either Blizzard or Bonneville. QTL on $1 \mathrm{AL}$ and 7AL were associated both with $\mathrm{CB}$ and $\mathrm{DB}$, whereas the QTL on 1BS only conferred resistance to $\mathrm{CB}$ and the QTL on 7DS 
was only effective against DB (Tables 2, 3, Fig. 2). The QTL on $1 \mathrm{AL}, 1 \mathrm{BS}$ and $7 \mathrm{AL}$ were detected in both populations, while the 7DS QTL was only detected in MP-BLI.

QBt.ifa-1AL had a major effect on CB and DB across all test environments (Tables 2, 3, Fig. 2) and was positioned on the long arm of chromosome $1 \mathrm{~A}$ close to the centromere. QTL intervals spanned a total genetic distance of $8 \mathrm{cM}$ (498.5-513.7 Mbp) for CB incidence and $15.3 \mathrm{cM}$ (498.5-516.6 Mbp) for DB incidence. Across both populations, phenotypic variance (PV) explained by QBt.ifa$1 A L$ averaged $32.5 \%$ for $\mathrm{CB}$ and $28 \%$ for DB incidence and ranged from 16.7 (DB.f16, MP-BLI) to $44.1 \%$ (CB.gh16, MP-BON).

QBt.ifa- $1 B S$ was a constant and main component of CB incidence in both mapping populations, accounting for 40 to $59 \%$ of the observed variation, but it had no effect on DB. QBt.ifa- $1 B S$ was positioned on the distal end of the short arm of chromosome 1B at 8-22 Mbp in the acrosspopulation analysis (Table 2, Fig. 2). The QTL peak was closely associated with SSR markers gwm374 and gwm264 in both populations.

While QBt.ifa-7AL significantly contributed to CB resistance in all field experiments of both populations, where it explained $15.4-25.6 \%$ of the PV, it was not detected under greenhouse conditions (Table 2). The 7A QTL had a smaller effect on DB, accounting for 9.8-19\% of the PV (Table 3). It was detected across all DB experiments on the MP-BLI population but was not significantly associated in the MPBON DB.f15 trial. QBt.ifa-7AL mapped near the telomere of the long arm of chromosome 7A at 722-737 Mbp (Fig. 2).

The minor effect QTL QBt.ifa-7DS was only associated with DB in the MP-BLI population (Table 3). QBt.ifa-7DS mapped near the distal end of the short arm of chromosome 7D at 12.5-15.3 Mbp (Fig. 2), a region colocalizing with 16 tightly linked markers. The QTL interval was unlinked to the rest of chromosome 7D by approximately $100 \mathrm{Mbp}$ due to the absence of detectable marker polymorphisms across this large interval.

Epistatic interactions on $\mathrm{CB}$ were identified between QBt.ifa-1BS:QBt.ifa-1AL and QBt.ifa-1BS:QBt.ifa-7AL in MP-BLI, MP-BON, and MP-CON and between QBt.ifa1AS:QBt.ifa-7AL in the MP-BLI population (Table 2, Fig. 3, Fig. 4). Furthermore, DB experiments revealed significant interactions between QBt.ifa-1AS:QBt.ifa-7AL in the MPBLI DB.f15 experiment and in the consensus analysis across populations (Table 3 ).

\section{KASP markers and QTL validation}

A set of 26 KASP markers was used for SNP haplotype screening across the QBt.ifa-1AL, QBt.ifa-1BS, QBt.ifa-7AL, and $Q B t$.ifa-7DS QTL intervals in the resistance donors, the recipient parents, the bunt differential lines and a panel of
57 genotypes. Genotyping revealed that, depending on the KASP marker, between 12 and $83 \%$ of the tested genotypes had the same SNP call as the resistance donors Blizzard and Bonneville (Table S8). Notably, Blizzard, Bonneville and bunt differential line 'Ridit' (Bt3) shared the same SNP haplotype across the entire QBt.ifa-1AL interval.

$\mathrm{BC}_{1}$-RILs of the validation population were selectively genotyped for their allele status at QBt.ifa-1AL, QBt.ifa-1BS, and QBt.ifa-7AL using four KASP markers per QTL. Lines were subdivided according to their QTL combinations, and the corresponding overall CB incidence BLUEs of grouped lines were compared. Subgroups carrying the resistance conferring allele only at single QTL or at multiple loci were all highly resistant and not significantly different from each other, with mean performances ranging from 0.4 to $8.7 \%$. In contrast, lines without any resistance QTL showed a mean incidence of $37.7 \%$ and were significantly more diseased than all other groups (Fig. 5).

\section{Discussion}

High levels of CB and DB incidence in the susceptible parents, check cultivars and some $B t$ differential lines confirmed that inoculation was successful and that disease pressure was high (Table 1, Table S3). CB incidence levels were higher in the greenhouse than in the field (Table 1). Similarly, Knox et al. (1998), Wang et al. (2009) and Laroche et al. (2000) reported much higher CB infection levels under controlled growth chamber than in field trials. The same $\mathrm{CB}$ spore mixture was used as inoculum for $\mathrm{CB}$ field and greenhouse trials. However, the bunt differential lines demonstrated a broader virulence spectrum in the greenhouse (Table S3), possibly due to environment dependent interactions between $B t$ resistance genes and the pathotype composition (Gaudet and Puchalski 1995). CB infection is optimal at soil temperatures of $5-10{ }^{\circ} \mathrm{C}$ (Purdy and Kendrick 1963), and sustained low temperatures during early plant development can decrease host plant resistance and subsequently increase disease incidence (Gaudet and Puchalski 1995; Griffith et al. 1955; Smith 1932; Zscheile 1956). The duration of the cold period strongly effected bunt expression (Zeischle 1956). We vernalised all seedlings at a constant temperature of $4{ }^{\circ} \mathrm{C}$ for eight weeks. Similar environmental conditions are unlikely to occur in the field. We thus hypothesize, that the specific vernalisation and greenhouse conditions probably increased disease incidence in our greenhouse experiment. Interaction between $B t$ incidence and environment has been previously reported and agree with our results (He and Hughes 2003; Knox et al. 1998; Laroche et al. 2000; Wang et al. 2009).

Sustained low temperatures, moisture and low light levels are most conducive for DB infection, and such conditions are 


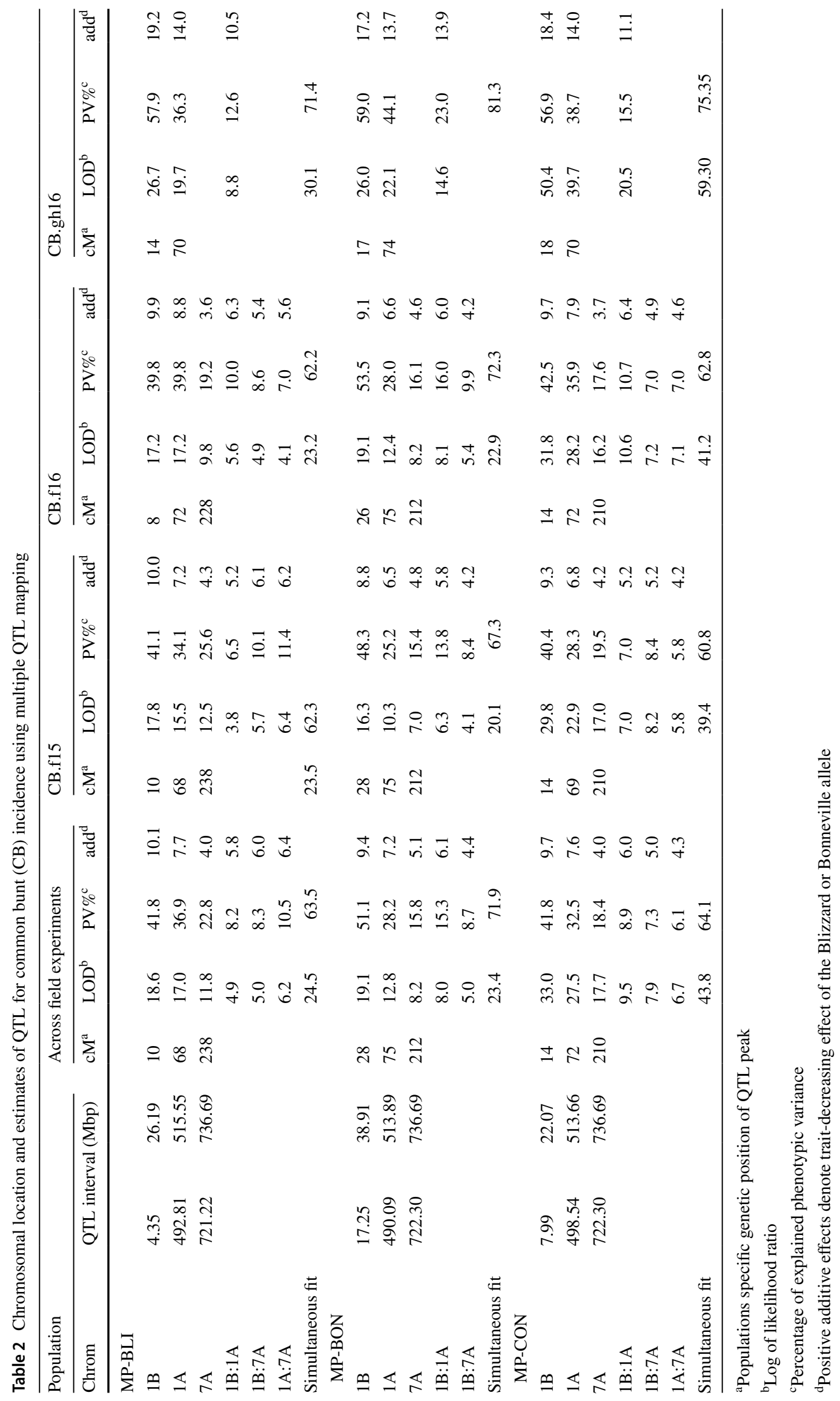




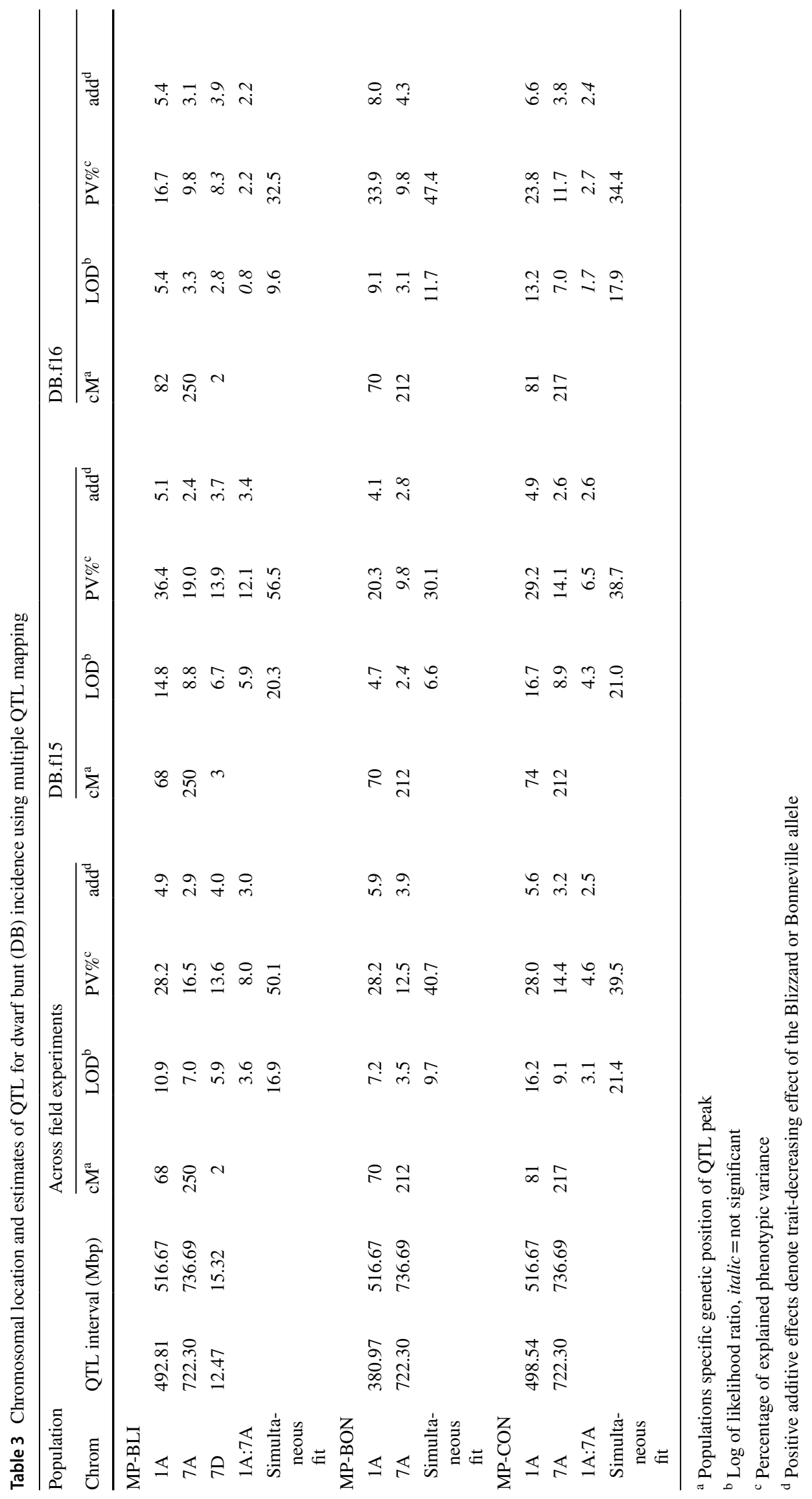



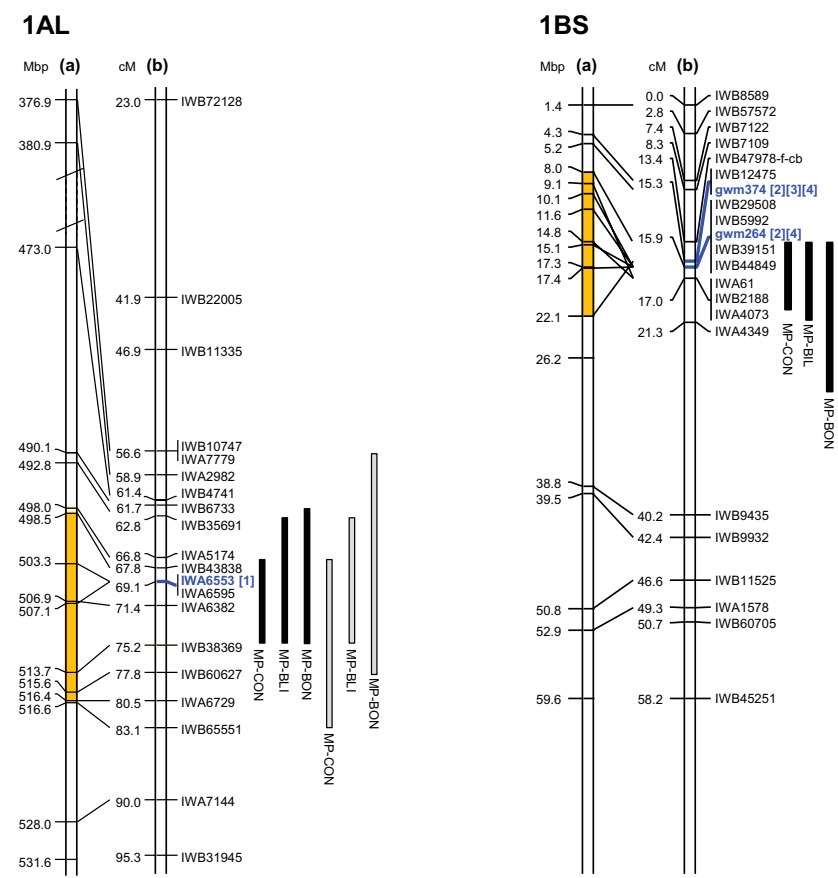

Fig. 2 Physical and genetic maps of linkage groups containing QTL. Only relevant subsections of the chromosomes and reduced numbers of markers are shown. All linkage groups and markers with their positions are shown in Online Resource Table S7. (a) Mbp positions of markers are derived from IWGSC RefSeq v1.0, (b) genetic cM positions are obtained from MP-CON. QTL bars for CB resistance (black) and DB resistance (gray) are based on the BLUEs across $\mathrm{CB}$ or DB experiments of the MP-BLI, MP-BON and MP-CON popula-
7AL

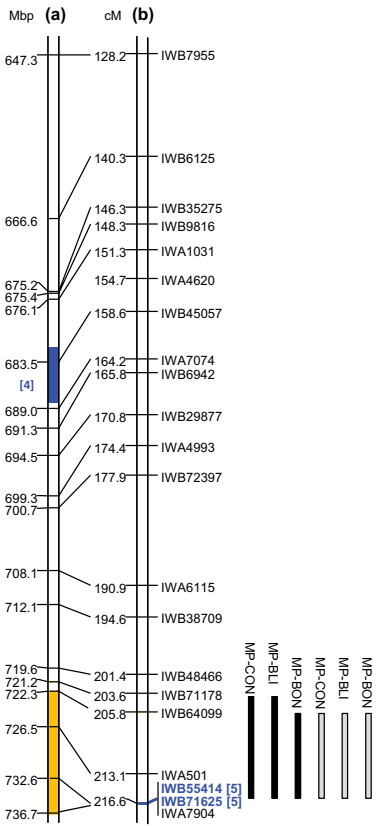

7DS

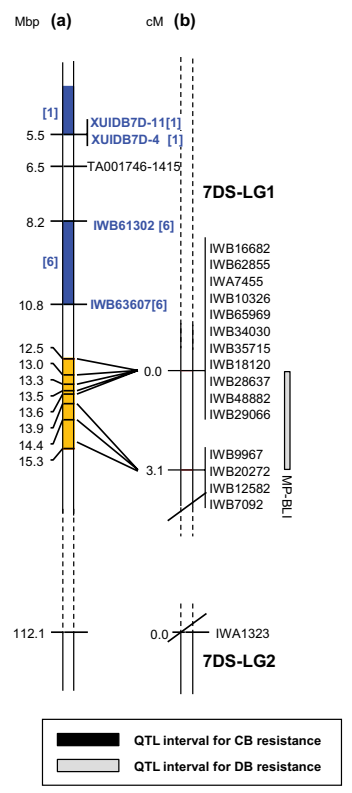

tions. QTL bars span a LOD drop of 1.5 from the maximum LOD. Yellow segments within chromosome bars indicate the corresponding physical length of the QTL in the MP-CON map. Blue segments and markers highlighted in bold letters in blue color refer to positions of published QTL. Numbers in brackets designate the following refences: [1] Chen et al. (2016), [2] Wang et al. (2009), [3] Singh et al. (2016), [4] Fofana et al. (2008), [5] Wang et al. (2019), and [6] Muellner et al. (2020)
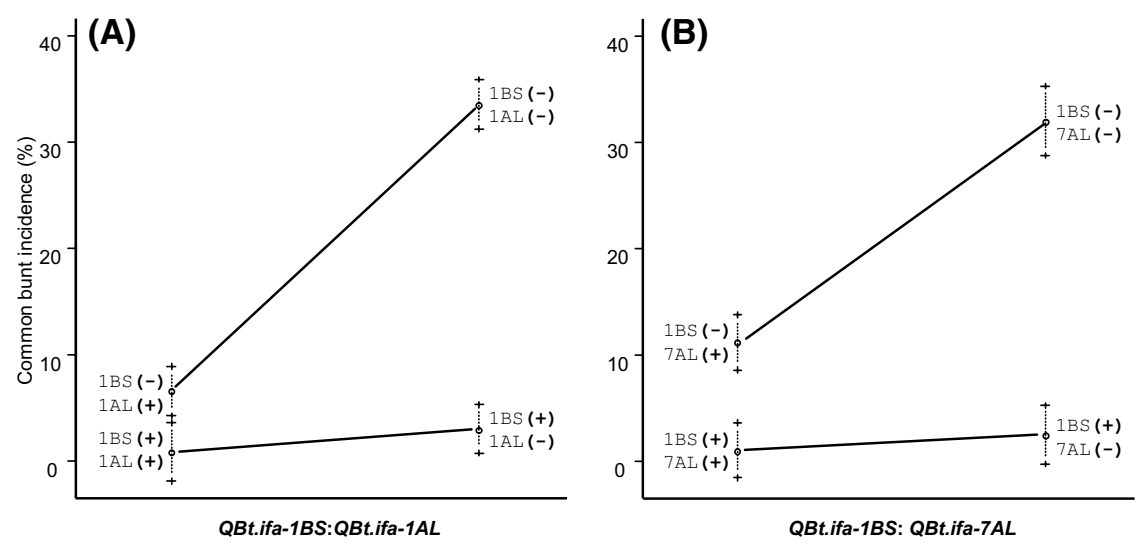

Fig. 3 Epistatic interactions on common bunt incidence across field experiments between (a) QBt.ifa-1BS:QBt.ifa-1AL, (b) QBt.ifa1BS:QBt.ifa-7AL and (c) QBt.ifa-1AL:QBt.ifa-7AL. (+) indicates the

most reliably provided by persistent snow cover (Tyler and Jensen 1958). DB infection in both populations was low in the DB.f15 trial, likely due to the shorter duration of snow cover than in the DB.f16 experiment. However, genotype was the main source of variance and heritability was high presence of the resistant allele and (-) indicates the absence of the resistant allele. Error bars of phenotypic means are plotted as \pm 1 standard error

for $\mathrm{DB}$ and $\mathrm{CB}$ incidence, indicating that the observed variation among the tested lines was mainly due to genetic effects (Table 1, Table S4). The DB inoculum of US origin possessed a broader virulence spectrum than the Austrian CB inoculum (Table S3). A similar result was obtained by Huber 


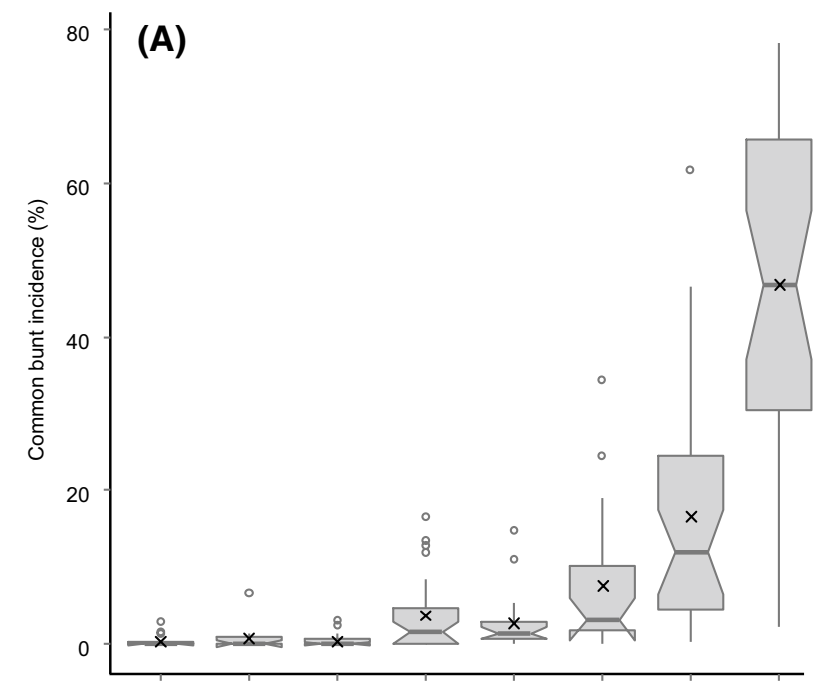

$\begin{array}{lcccccccc}\text { QBt.ifa-1AL } & + & + & - & + & - & + & - & - \\ \text { QBt.ifa-1BS } & + & + & + & - & + & - & - & - \\ \text { QBt.ifa-7AL } & + & - & + & + & - & - & + & - \\ \text { Nbo of lines } & 14 & 13 & 28 & 26 & 27 & 23 & 33 & 33 \\ \text { Mean } & 0.6^{\mathrm{a}} & 1.0^{\mathrm{a}} & 1.1^{\mathrm{a}} & 6.4^{\mathrm{a}} & 3.6^{\mathrm{a}} & 8.7^{\mathrm{a}} & 28.2^{\mathrm{b}} & 54.6^{\mathrm{c}} \\ \text { SD } & 1.2 & 1.9 & 1.8 & 6.4 & 4.1 & 9.1 & 17.9 & 23.5\end{array}$

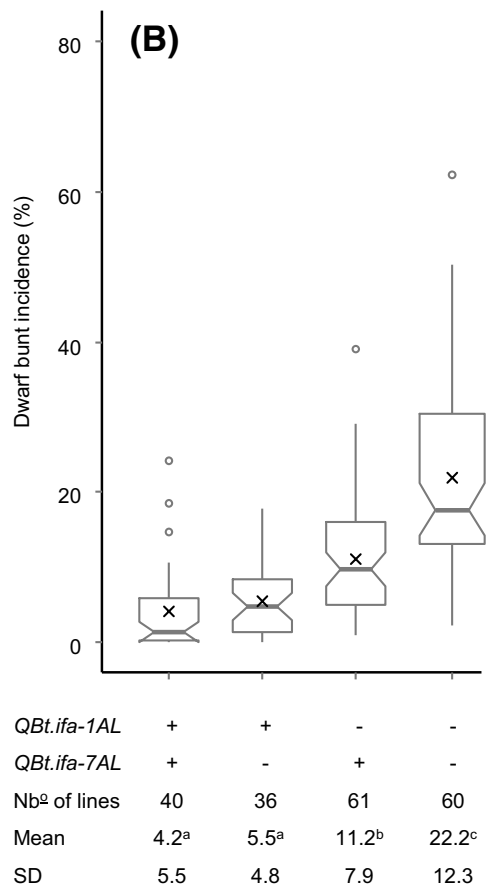

ence of resistant allele;-denotes absence of resistant allele), the number of lines, and bunt incidence means and standard deviations (SD) are provided. Groups with different letters are significantly different $(p<0.05)$ based on a Tukey HSD test. Boxplots are based on BLUEs across field trials

virulence spectrum between the applied CB and DB inocula are the likely cause of this discrepancy (Table S3). That $Q B t$. if $a-1 B S$ specifically confers $C B$ resistance is supported by its colocalization with a major QTL for CB resistance on chromosome 1B (Wang et al. 2009) and its lack of association with DB (Chen et al. 2016) in independent mapping populations with either Blizzard or 'IDO444', which is a full-sib of Blizzard, as resistance donors. Earlier studies assigned Bt4, Bt5 and Bt6 to chromosome 1B (McIntosh et al. 1998; Schmidt et al. 1969), making them putative candidate genes for QBt.ifa-1BS. However, KASP marker validation revealed that the bunt differential lines $B t 4, B t 5$, and $B t 6$ had different haplotypes than the resistance donors Blizzard and Bonneville across the QBt.ifa-lBS interval, suggesting that the resistance of QBt.ifa-1BS differs from that of $B t 4, B t 5$ and $B t 6$ (Table S8). Several studies identified major and minor QTL for CB resistance on chromosome 1B in independent mapping populations (Dumalasova et al. 2012; Fofana et al. 2008; Galaev et al. 2018; Singh et al. 2016; Wang et al. 2009; Zou et al. 2017). Of these, QTL reported by Fofana et al. (2008), Wang et al. (2009) and Singh et al. (2016) were located near the SSR marker $g w m 264$ and thus coincided with the QTL region of QBt.ifa-1BS (Fig. 2). The resistance donors of these QTL included 'AC Domain' (Fofana et al. 2008), Blizzard (Wang et al. 2009) and 'Carberry' (Singh 


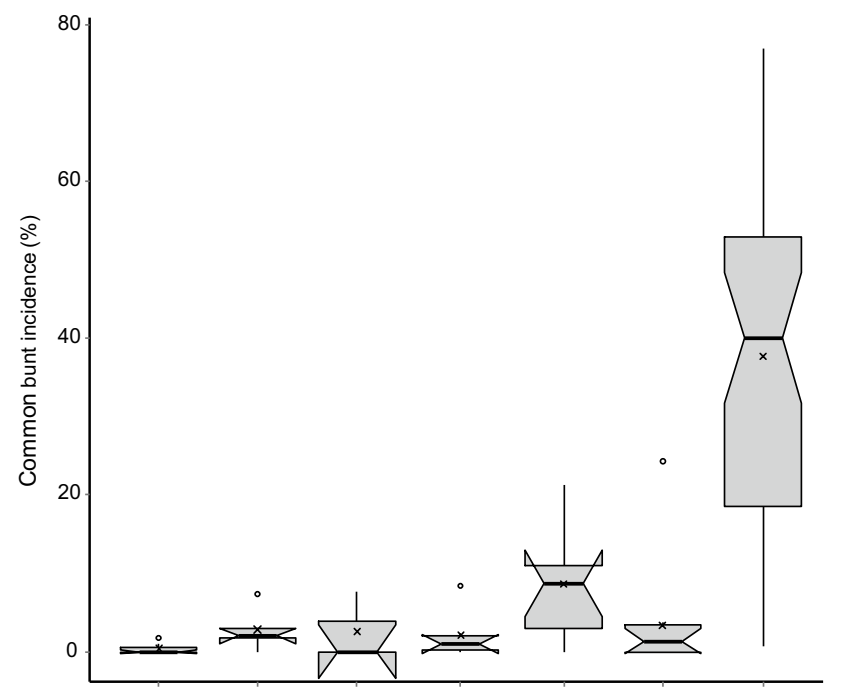

$\begin{array}{lccccccc}\text { QBt.ifa-1AL } & + & - & + & - & + & - & - \\ \text { QBt.ifa-1BS } & + & + & - & + & - & - & - \\ \text { QBt.ifa-7AL } & - & + & + & - & - & + & - \\ \text { Nbo of lines } & 7 & 5 & 3 & 6 & 9 & 12 & 43 \\ \text { Mean } & 0.4^{\mathrm{a}} & 2.8^{\mathrm{a}} & 2.5^{\mathrm{a}} & 2.1^{\mathrm{a}} & 8.7^{\mathrm{a}} & 3.3^{\mathrm{a}} & 37.6^{\mathrm{b}} \\ \mathrm{SD} & 0.7 & 2.8 & 4.4 & 3.1 & 7.2 & 6.7 & 21.1\end{array}$

Fig. 5 Boxplot of common bunt incidence (\%) BLUEs of BC-RILs of the validation population, grouped by their QTL combinations. Medians are indicated by solid horizontal bold lines, means by crosses, and outliers by open circles. For each QTL combination group, QTL genotypes (+ denotes presence of resistant allele;- - denotes absence of resistant allele), the number of lines, and bunt incidence means and standard deviations (SD) are provided. Groups with different letters are significantly different $(p<0.05)$ based on a Tukey HSD test

et al. 2016). Based on pedigree information, it remains unclear whether the $\mathrm{CB}$ resistance QTL on chromosome 1B from AC Domain and Carberry is identical to QBt.ifa-1BS. Further comparative studies are necessary to clarify this.

QBt.ifa-1AL, located on chromosome 1A at 498.5-516.6 Mbp, was a main and constant source of CB and DB resistance in both populations and in all test environments (Table 2, Fig. 2). Because QBt.ifa- $1 A L$ coincided with the DB resistance QTL Q.DB.ui-1A reported by Chen et al. (2016) and because the donor of Q.DB.ui-1A (IDO444, full-sib of Blizzard) is closely related to Blizzard and Bonneville (Table S1), we assume that the QTL underlying the resistance gene at $Q B$ t.ifa- $1 A L$ and Q.DB.ui- $1 A$ are identical by descent. KASP marker validation revealed that Blizzard, Bonneville and the bunt differential cultivar 'Ridit' (Bt3) had the same SNP haplotype for all eight KASP markers across the entire QBt.ifa-1AL interval (Table S8). Ridit expressed high but incomplete resistance (1.6-9.1\% bunt incidence) in all CB and DB test environments (Table S3), similar to genotypes that were carriers of QBt.ifa-1AL only (Figs. 3, 4). The chromosomal location of $B t 3$ is yet unknown. Given that Ridit appears in the pedigrees of Blizzard, Bonneville and IDO444, QBt.ifa-1AL may represent the bunt resistance gene $B t 3$.

QBt.ifa-7AL had a moderate effect on CB and DB incidence in all field trials but had no effect in the greenhouse experiment. This indicates that expression of specific resistance genes may depend on environmental conditions, particularly on the temperature during early plant development, and that greenhouse experiments only partially reflect the complex interplay of pathogen, host plant genotype and environment. The QTL interval of QBt.ifa-7AL mapped near the telomere of chromosome 7AL and coincided with the major DB resistance QTL Q.DB.ui-7AL derived from the DB resistant line 'IDO835' (Wang et al. 2019). Blizzard, Bonneville, and IDO835 share the highly bunt resistant breeding line 'PI 476212' (Sunderman et al. 1986) in their pedigrees (https://www.ars-grin.gov/). Thus, PI 476212 may be the resistance donor of both QBt.ifa-7AL and Q.DB.ui$7 A L$. This is further supported by KASP marker screening, from which Blizzard, Bonneville, and PI 476212 showed identical SNP haplotypes for all KASP markers across the 7AL QTL interval (Table S8).

QBt.ifa-7DS was only associated with DB in the MPBLI population and its effect on DB incidence was relatively small (Table 3). QBt.ifa-7DS mapped near the distal end of the short arm of chromosome 7D, approximately 7 Mbp from Q.DB.ui-7DS and $2 \mathrm{Mbp}$ from the bunt resistance gene QBt.ifa-7D|Bt12 (Fig. 2). Q.DB.ui-7DS (Chen et al. 2016), QBt.ifa-7D|Bt12 (Muellner et al. 2020) and QBt.ifa-7DS (current study) all faced the same problem of a lack of marker polymorphisms flanking the QTL, so that associated markers physically span relatively short intervals that are unlinked from the rest of chromosome 7D. These physically large monomorphic intervals, however, complicated precisely mapping of QTL positions and map comparisons. Q.DB.ui-7DS, QBt.ifa-7D|Bt12 and QBt.ifa$7 D S$ possessed the same marker haplotype at Q.DB.ui$7 D S$ (wPt-2565) and at all markers distal to Q.DB.ui-7DS (Jianli Chen, University of Idaho, personal communication). Unfortunately, all markers informative for Q.DB.ui$7 D S$ were monomorphic for QBt.ifa-7D|Bt12 and QBt.ifa$7 D S$. There was a notable difference in effect size between Q.DB.ui-7DS (> 50\%), and QBt.ifa-7DS (12\%), which may be due to differences in physical positions of polymorphic markers between the two mapping populations. Markers associated with the major bunt resistance gene $B t 12$ are physically positioned between Q.DB.ui-7DS and QBt.ifa$7 D S$ (Fig. 2), but the precise location of $B t 12$ is unknown as well. Bt12 has been reported to have a major impact on $\mathrm{CB}$ and only a minor to moderate one on DB resistance (Muellner et al. 2020). This is in contrast to Chen et al. (2016), who reported a strong effect on DB, and our finding that $Q B t . i f a-7 D S$ conferred resistance to DB only. Resistance of $B t 12$ was derived from the $B t$ differential 
line 'PI 119333'. Since PI 119333 is genetically unrelated to IDO444 and Blizzard, it remains unclear whether Bt12 represents the same resistance allele as QBt.ifa-7DS and/ or Q.DB.ui-7DS.

Epistatic interactions were substantial for $\mathrm{CB}$ resistance but were only weakly expressed for DB (Tables 2, 3). QTL by QTL interactions were observed in which the effect of one QTL was masked by the presence of a second major QTL, and genotypes with only one QTL appeared to be almost as resistant as genotypes that possessed two or more resistance QTL (Figs. 3, 4, 5). Epistatic interactions between bunt resistance QTL were also found by Chen et al. (2016), Knox et al. (2013) and Singh et al. (2016). Epistasis is a common phenomenon when two or more large effect resistance genes, which can replace each other, segregate in a population (also known as duplicated gene action).

The bunt resistance QTL QBt.ifa-1BS, QBt.ifa-1AL, and $Q B t . i f a-7 A L$ identified in the mapping populations (Fig. 4) were successfully verified in the validation population (Fig. 5). The selected KASP markers have also been employed to track the transmission of the respective resistance QTL in an internal backcrossing program (results not shown) and are thus well suitable for marker-assisted selection (MAS). However, none of the currently available markers is diagnostic for a bunt resistance QTL. Markers are linked to the QTL and their usefulness must be tested in any given breeding program and might diminish by ongoing recombination. Hence, we recommend relying on flanking markers for tracking resistance QTL to minimize the frequency of false positives during MAS and QTL introgression.

In conclusion, Bonneville and Blizzard represent modern winter wheat types, combining acceptable agronomic and quality traits with high and durable resistance to $\mathrm{CB}$ and $\mathrm{DB}$. Bonneville is still used in dryland production, whereas Blizzard is out of production but has been used as a source of DB resistance worldwide (Jianli Chen, University of Idaho, personal communication). These cultivars share durable bunt resistance, which appears to originate from a combination of several small and large effect QTL. SNP markers linked to these QTL can be exploited for breeding a new generation of productive and bunt resistant cultivars, which should possess various combinations of resistance genes to ensure long-lasting protection against these fungal diseases.

Acknowledgements We thank Herbert Huss and AGES for collecting and providing CB inoculum. We acknowledge Matthias Fidesser for technical support for the CB field trials. We thank Michael Haag and Mathias Schneider for assisting in the CB scorings. We are grateful to Verena Strasser for her work on KASP genotyping. Many thanks to Laura Morales and Magdalena Ehn for critically reviewing the manuscript. We thank Jianli Chen and Riu Wang (University of Idaho, Aberdeen) for genotyping the parental lines with their KASP markers.
Author contribution statement AEM and MB analyzed the data and wrote the manuscript. AEM conducted and supervised bunt experiments. MB designed and performed KASP assays. BE, JFH, BP and $\mathrm{RP}$ assisted in phenotyping and genotyping. DH conducted the DB field trials. SM helped with the statistical analysis. HB initiated and guided the study and obtained funding. All authors read and approved the final manuscript.

Funding Open access funding provided by University of Natural Resources and Life Sciences Vienna (BOKU). This work was financed by the Austrian Federal Ministry of Agriculture, Forestry, Environment and Water Management within the framework of the ERA-Net project Core Organic 2 (Project Number 100898). Open access funding was provided by University of Natural Resources and Life Sciences Vienna (BOKU).

\section{Compliance with ethical standards}

Conflict of interest The authors declare that they have no conflicts of interest.

Ethical standard The authors declare that the experiments conducted for this publication comply with the current laws of Austria.

Open Access This article is licensed under a Creative Commons Attribution 4.0 International License, which permits use, sharing, adaptation, distribution and reproduction in any medium or format, as long as you give appropriate credit to the original author(s) and the source, provide a link to the Creative Commons licence, and indicate if changes were made. The images or other third party material in this article are included in the article's Creative Commons licence, unless indicated otherwise in a credit line to the material. If material is not included in the article's Creative Commons licence and your intended use is not permitted by statutory regulation or exceeds the permitted use, you will need to obtain permission directly from the copyright holder. To view a copy of this licence, visit http://creativecommons.org/licenses/by/4.0/.

\section{References}

Aboukhaddour R, Fetch T, McCallum BD, Harding MW, Beres BL, Graf RJ (2020) Wheat diseases on the prairies: a Canadian story. Plant Pathol 69:418-432. https://doi.org/10.1111/ppa.13147

Alaux M, Rogers J, Letellier T, Flores R, Alfama F, Pommier C, Mohellibi N, Durand S, Kimmel E et al (2018) Linking the international wheat genome sequencing consortium bread wheat reference genome sequence to wheat genetic and phenomic data. Genome Biol 19:111. https://doi.org/10.1186/s13059-018-1491-4

Bhatta M, Morgounov A, Belamkar V, Yorgancilar A, Baenziger PS (2018) Genome-wide association study reveals favorable alleles associated with common bunt resistance in synthetic hexaploid wheat. Euphytica 214:200. https://doi.org/10.1007/s1068 1-018-2282-4

Bokore FE, Cuthbert RD, Knox RE, Singh A, Campbell HL, Pozniak CJ, N'Diaye A, Sharpe AG, Ruan Y (2019) Mapping quantitative trait loci associated with common bunt resistance in a spring wheat (Triticum aestivum L.) variety Lillian. Theor Appl Gene 132:3023-3033. https://doi.org/10.1007/s00122-019-03403-3

Borgen A, Davanlou M (2000) Biological control of common bunt (Tilletia tritici). J Crop Prod 3:157-171. https://doi.org/10.1300/ J144v03n01_14 
Bray JR, Curtis JT (1957) An ordination of the upland forest communities of Southern Wisconsin. Ecol Monogr 27:325-349. https://doi. org/10.2307/1942268

Broman KW, Wu H, Sen S, Churchill GA (2003) R/qtl: QTL mapping in experimental crosses. Bioinformatics 19:889-890. https://doi. org/10.1093/bioinformatics/btg112

Chen JL, Guttieri MJ, Zhang JL, Hole D, Souza E, Goates B (2016) A novel QTL associated with dwarf bunt resistance in Idaho 444 winter wheat. Theor Appl Gene 129:2313-2322. https://doi. org/10.1007/s00122-016-2783-2

Christensen CM (1957) Biology and control of the smut fungi. AIBS Bull 7:52-52. https://doi.org/10.2307/1292466

Dumalasova V, Simmonds J, Bartos P, Snape J (2012) Location of genes for common bunt resistance in the European winter wheat cv. Trintella Euphytica 186:257-264. https://doi.org/10.1007/ s10681-012-0671-7

Flor HH (1956) The complementary genic systems in flax and flax rust joint contribution from the field crops research branch, agricultural research service, united states department of agriculture and the north dakota agricultural experiment station. In: Demerec M (ed) Advances in genetics. Academic Press, New York, pp 29-54

Fofana B, Humphreys DG, Cloutier S, McCartney CA, Somers DJ (2008) Mapping quantitative trait loci controlling common bunt resistance in a doubled haploid population derived from the spring wheat cross RL4452 x AC Domain. Mol Breed 21:317-325. https ://doi.org/10.1007/s11032-007-9131-9

Galaev A, Babayants LT, Sivolap YM (2018) DNA-markers for resistance to common bunt transferred from Aegilops cylindrica Host to hexaploid wheat. Czech J Gene Plant Breed 42:62-65. https:// doi.org/10.17221/6234-CJGPB

Gaudet DA, Puchalski BJ (1989) Status of bunt resistance in Western Canadian spring wheat and triticale. Can J Plant Sci 69:797-804. https://doi.org/10.4141/cjps89-095

Gaudet DA, Puchalski BJ (1995) Influence of temperature on interaction of resistance genes in spring wheat differentials with races of common bunt (Tilletia tritici and T. laevis). Can J Plant Sci 75:745-749. https://doi.org/10.4141/cjps95-126

Gilmour AR, Gogel BJ, Cullis BR, Welham SJ, Thompson R (2015) ASReml user guide release 4.1 functional specification. VSN International Ltd, Hemel Hempstead, HP1 1ES, UK www.vsni. co.uk

Goates BJ (1996) Common bunt and dwarf bunt. In: Wilcoxson RD, Saari EE (eds) Bunt and smut diseases of wheat: concepts and methods of disease management. CIMMYT, Mexico, D.F., pp $12-25$

Goates BJ (2012) Identification of new pathogenic races of common bunt and dwarf bunt fungi, and evaluation of known races using an expanded set of differential wheat lines. Plant Dis 96:361-369. https://doi.org/10.1094/pdis-04-11-0339

Goates BJ, Bockelman HE (2012) Identification of new sources of high levels of resistance to dwarf bunt and common bunt among winter wheat landraces in the USDA-ARS national small grains collection. Crop Sci 52:2595-2605. https://doi.org/10.2135/crops ci2012.01.0060

Goates BJ, Peterson GL (1999) Relationship between soilborne and seedborne inoculum density and the incidence of dwarf bunt of wheat. Plant Dis 83:819-824. https://doi.org/10.1094/ pdis.1999.83.9.819

Gordon T, Wang R, Hole D, Bockelman H, Michael Bonman J, Chen J (2020) Genetic characterization and genome-wide association mapping for dwarf bunt resistance in bread wheat accessions from the USDA national small grains collection. Theor Appl Gene 133:1069-1080. https://doi.org/10.1007/s00122-020-03532-0

Griffith RB, Zscheile FP, Oswald JW (1955) The influence of certain environmental factors on expression of resistance to bunt in wheat. Phytopathology 45:428-434
He C, Hughes GR (2003) Inheritance of resistance to common bunt in spelt and common wheat. Can J Plant Sci 83:47-56. https://doi. org/10.4141/P01-167

Hoffmann JA (1982) Bunt of wheat. Plant Dis 66:979-987. https://doi. org/10.1094/PD-66-979

Hoffmann JA, Metzger RJ (1976) Current status of virulence genes and pathogenic races of wheat bunt fungi in northwestern USA. Phytopathology 66:657-660. https://doi.org/10.1094/Phyto-66-657

Holton CS (1954) Natural hybridization between common and dwarf bunt as related to the problem of delimitation of species of Tilletia occurring on wheat. Phytopathology 44:493

Huber K, Buerstmayr H (2006) Development of methods for bunt resistance breeding for organic farming. Czech J Gene Plant Breed 42:66-71. https://doi.org/10.17221/6235-CJGPB

Knox RE, Campbell HL, Depauw RM, Gaudet D, Puchalski B, Clarke FC (2013) DNA markers for resistance to common bunt in "McKenzie" wheat. Can J Plant Path 35:328-337. https://doi. org/10.1080/07060661.2013.763292

Knox RE, Fernandez MR, Brule-Babel AL, DePauw RM (1998) Inheritance of common bunt resistance in androgenetically derived doubled haploid and random inbred populations of wheat. Crop Sci 38:1119-1124. https://doi.org/10.2135/crops ci1998.0011183X003800050002x

Laroche A, Demeke T, Gaudet DA, Puchalski B, Frick M, McKenzie R (2000) Development of a PCR marker for rapid identification of the Bt-10 gene for common bunt resistance in wheat. Genome 43:217-223. https://doi.org/10.1139/gen-43-2-217

Lowe I, Jankuloski L, Chao S, Chen X, See D, Dubcovsky J (2011) Mapping and validation of QTL which confer partial resistance to broadly virulent post-2000 North American races of stripe rust in hexaploid wheat. Theor Appl Gene 123:143-157. https ://doi.org/10.1007/s00122-011-1573-0

Matanguihan JB, Murphy KM, Jones SS (2011) Control of common bunt in organic wheat. Plant Dis 95:92-103. https://doi. org/10.1094/pdis-09-10-0620

McIntosh R, Hart G, Devos K, Gale M, Rogers W (1998) Catalogue of gene symbols for wheat. https://wheat.pw.usda.gov/ggpages/ wgc/98/. Accessed 8 May 2020

Menzies JG, Knox RE, Popovic Z, Procunier JD (2006) Common bunt resistance gene $B t 10$ located on wheat chromosome $6 \mathrm{D}$. Can J Plant Sci 86:1409-1412. https://doi.org/10.4141/p06-106

Metzger RJ, Hoffmann JA (1978) New races of common bunt useful to determine resistance of wheat to dwarf bunt. Crop Sci 18:49-51. https://doi.org/10.2135/cropsci1978.0011183X00 $1800010013 \mathrm{x}$

Mourad AMI, Sallam A, Belamkar V, Mahdy E, Bakheit B, Abo El-Wafaa A, Stephen Baenziger P (2018) Genetic architecture of common bunt resistance in winter wheat using genomewide association study. BMC Plant Biol 18:280. https://doi. org/10.1186/s12870-018-1435-x

Muellner AE, Eshonkulov B, Hagenguth J, Pachler B, Michel S, Buerstmayr M, Hole D, Buerstmayr H (2020) Genetic mapping of the common and dwarf bunt resistance gene Bt12 descending from the wheat landrace. Euphytica. https://doi.org/10.1007/ s10681-020-02614-w

Nguyen HDT, Sultana T, Kesanakurti P, Hambleton S (2019) Genome sequencing and comparison of five Tilletia species to identify candidate genes for the detection of regulated species infecting wheat. IMA Fungus 10:11. https://doi.org/10.1186/ s43008-019-0011-9

Piepho H-P, Möhring J (2007) Computing heritability and selection response from unbalanced plant breeding trials. Genetics 177:1881-1888. https://doi.org/10.1534/genetics.107.074229

Purdy LH, Kendrick EL (1963) Influence of environmental factors on the development of wheat bunt in the Pacific Northwest. 
IV. Effect of soil temperature and moisture on infection by soil spores. Phytopathology 53:416-418

R Core Team (2016) R: A language and environment for statistical computing. $\mathrm{R}$ foundation for statistical computing, Vienna, Austria. URL https://www.R-project.org/

Röder MS, Korzun V, Wendehake K, Plaschke J, Tixier MH, Leroy P, Ganal MW (1998) A microsatellite map of wheat. Genetics 149:2007-2023

Russell PE (2005) A century of fungicide evolution. J Agric Sci 143:11-25. https://doi.org/10.1017/S0021859605004971

Saari EE, Mamluk OF, Burnett P (1996) Bunts and smuts of wheat. In: Wilcoxson RD, Saari EE (eds) Bunt and smut diseases of wheat: concepts and methods of disease management. CIMMYT, Mexico, D.F.

Saghai-Maroof MA, Soliman KM, Jorgensen RA, Allard RW (1984) Ribosomal DNA spacer-length polymorphisms in barley: mendelian inheritance, chromosomal location, and population dynamics. Proc Natl Acad Sci USA 81:8014-8018. https://doi. org/10.1073/pnas.81.24.8014

Schmidt JW, Morris R, Johnson VA (1969) Monosomic analysis for bunt resistance in derivatives of Turkey and Oro wheats 1 . Crop Sci 9:286-288. https://doi.org/10.2135/cropsci1969.00111 83X000900030009x

Sen S, Churchill GA (2001) A statistical framework for quantitative trait mapping. Genetics 159:371-387. https://doi.org/10.1534/ genetics.107.071407

Singh A, Knox RE, DePauw RM, Singh AK, Cuthbert RD, Kumar S, Campbell HL (2016) Genetic mapping of common bunt resistance and plant height QTL in wheat. Theor Appl Gene 129:243-256. https://doi.org/10.1007/s00122-015-2624-8

Smith WK (1932) The effect of different temperatures on the reaction of Hope wheat to stinking smut. Phytopathology 22:615-627

Souza E, Windes JM, Sunderman DW, Whitmore J, Kruk M, Goates BJ (1995) Registration of 'Bonneville' hard red winter wheat. Crop Sci 35:1218-1219. https://doi.org/10.2135/cropsci199 5.0011183X003500040072x

Steffan PM, Torp AM, Borgen A, Backes G, Rasmussen SK (2017) Mapping of common bunt resistance gene $B t 9$ in wheat. Theor Appl Gene 130:1031-1040. https://doi.org/10.1007/s0012 2-017-2868-6

Sunderman DW, Hoffman JA, O'Connell BT (1986) Registration of four winter wheat germplasm lines with resistance to dwarf bunt. Crop Sci 26:651-652. https://doi.org/10.2135/cropsci198 6.0011183X002600030060x

Sunderman DW, Souza E, Birzer D, Whitmore J (1991) Registration of "Blizzard" wheat. Crop Sci 31:490-491. https://doi. org/10.2135/cropsci1991.0011183X003100020074x
Taylor J, Butler D (2017) R Package ASMap: Efficient genetic linkage map construction and diagnosis. J Stat Softw 79:1-29. https ://doi.org/10.18637/jss.v079.i06

Tyler LJ, Jensen NF (1958) Some factors that influence development of dwarf bunt in winter wheat. Phytopathology 48:565-571

van Ooijen JW (1992) Accuracy of mapping quantitative trait loci in autogamous species. Theor Appl Gene 84:803-811. https://doi. org/10.1007/bf00227388

Voorrips RE (2002) MapChart: software for the graphical presentation of linkage maps and QTLs. J Hered 93:77-78. https://doi. org/10.1093/jhered/93.1.77

Wang R, Gordon T, Hole D, Zhao W, Isham K, Bonman JM, Goates B, Chen J (2019) Identification and assessment of two major QTLs for dwarf bunt resistance in winter wheat line 'IDO835.' Theor Appl Gene 132:2755-2766. https://doi.org/10.1007/ s00122-019-03385-2

Wang S, Knox RE, DePauw RM, Clarke FR, Clarke JM, Thomas JB (2009) Markers to a common bunt resistance gene derived from "Blizzard" wheat (Triticum aestivum L.) and mapped to chromosome arm 1BS. Theor Appl Gene 119:541-553. https:// doi.org/10.1007/s00122-009-1063-9

Wang S, Wong D, Forrest K, Allen A, Chao S, Huang BE, Maccaferri M, Salvi S, Milner SG et al (2014) Characterization of polyploid wheat genomic diversity using a high-density 90,000 single nucleotide polymorphism array. Plant Biotechnol J 12:787-796. https://doi.org/10.1111/pbi.12183

Wilkinson PA, Winfield MO, Barker GLA, Tyrrell S, Bian X, Allen AM, Burridge A, Coghill JA, Waterfall C et al (2016) CerealsDB 3.0: expansion of resources and data integration. BMC Bioinform. https://doi.org/10.1186/s12859-016-1139-x

Woolman HM, Humphrey HB (1924) Summary of literature on bunt, or stinking smut, of wheat. U.S. Dept. of Agriculture, Washington, D.C.

Zou J, Semagn K, Chen H, Iqbal M, Asif M, N'Diaye A, Navabi A, Perez-Lara E, Pozniak C et al (2017) Mapping of QTLs associated with resistance to common bunt, tan spot, leaf rust, and stripe rust in a spring wheat population. Mol Breed 37:144. https://doi.org/10.1007/s11032-017-0746-1

Zscheile FP (1956) The influence of temperature on the expression of bunt in susceptible and resistant wheats. Phytopathology $46: 168-174$

Publisher's Note Springer Nature remains neutral with regard to jurisdictional claims in published maps and institutional affiliations. 